\title{
Correction to: A Review of the Techniques Used to Control Confounding Bias and How Spatiotemporal Variation Can Be Controlled in Environmental Impact Studies
}

\section{Rezvan Hatami}

Published online: 30 January 2020

(C) Springer Nature Switzerland AG 2020

Correction to: Water Air Soil Pollut (2019) 230: 132

https://doi.org/10.1007//11270-019-4150-9

Unfortunately, the Figure $1 \mathrm{~b}$ was incorrectly captured in the published online paper.

The blue arrow in Figure $1 \mathrm{~b}$ needs to be modified to the graph. The corrected Figure $1 \mathrm{~b}$ is shown in the next page. 
a

\section{Climate}

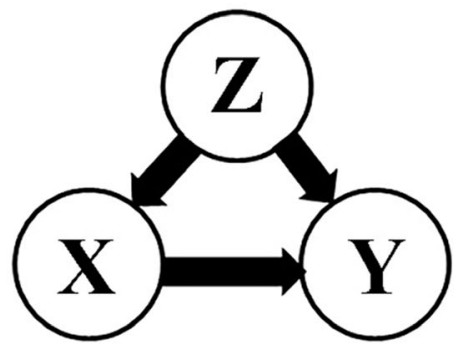

Wastewater quality

Aquatic biota

Figure 1. A graph demonstrating a confounding relationship between variables; a) the effect of wastewater on aquatic biota can be confounded by climate, b) the effect of temporal b Time

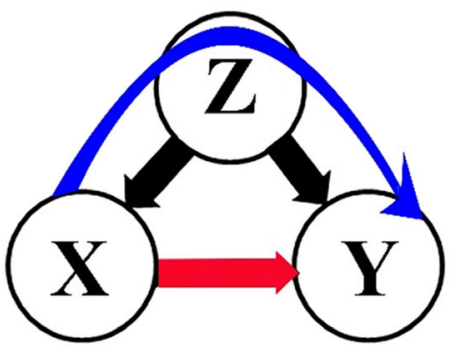

Wastewater quality

Aquatic biota

confounding related to variables e.g. temperature can be controlled via back door and front door 